\title{
Crosslinguistic lexical transfer of English-based loanwords in English L2 writing by Japanese university students
}

Nicolai Struc and Nicholas Wood* Reitaku University

\begin{abstract}
Research has shown tentative support for a "borrowed word effect" of English-based loanwords in Japanese (gairaigo) on written production in English by Japanese learners. This study interrogates a longitudinal learner corpus of argumentative and narrative writing by Japanese learners (NNS) and a corresponding NS corpus. Vocabulary profile analyses revealed: 1) NNS writing showed greater deployment of loanword cognate items than NS writing in both genres. 2) The deployment of loanword cognate items in NNS writing in both genres did not change over time. 3) NS writing showed greater deployment of loanword cognate items in narrative writing than argumentative writing, but NNS genres showed no difference. Keyword analysis and concordances of selected loanword cognate items revealed widespread and consistent patterns of ungrammaticality resembling L1 usage. Findings suggest Japanese writers heavily rely on loanword cognates. While loanword cognates arguably contribute to fluency, findings suggest potential for overreliance and negative transfer.
\end{abstract}

Key words: learner corpus, loanwords, crosslinguistic transfer, Japanese, English

* Principle contact:

Andrew Nicolai Struc, Associate Professor

Faculty of Foreign Studies, Reitaku University, Japan

Tel.: (+81) 4-7173-3033

E-mail: astruc@reitaku-u.ac.jp

Bergen Language and Linguistic Studies (BeLLS), May 30th 2015. (C) Struc and Wood DOI: $10.15845 /$ bells.v6i0.806

This is an Open Access article distributed under the terms of the Creative Commons Attribution License (http://creativecommons.org/licenses/by/3.0/). 


\section{Introduction}

It has been argued that gairaigo, or lexical items of foreign origin used in Japanese, provide a valuable resource for Japanese L2 learners of English (e.g. Brown and Williams 1985), enabling them to more readily access, acquire, and use the L2 words from which gairaigo are derived, and resulting in a relatively higher frequency usage of loanword cognate items in written texts or "borrowed word effect" (Daulton 2007). Before we investigate these propositions through the interrogation of a longitudinal learner corpus and a native-speaker corpus, we briefly locate gairaigo within its wider linguistic context, consider its usage, and review its potential as a learning tool.

According to Irwin (2011), gairaigo represent one feature of the diachronic lexical stratification of Japanese. The first two strata are represented by the core vocabulary of native Japanese and the fourth-century addition, Sino-Japanese, which is now wholly assimilated into the language. Gairaigo became extant from the late $16^{\text {th }}$ century with the establishment of international trade, and increasingly so after the opening of Japan in the mid- $19^{\text {th }}$ century as a consequence of renewed trade links and the importance given to Western philosophy, science, and technology - factors which continue to influence the choice of borrowings (Loveday 2008). The final stratum is comprised of hybrids which are pairings of the above (e.g. gairaigo + native).

As foreign loanwords, gairaigo are lexemes that have been "integrated with lesser or greater fidelity into the phonological and grammatical systems of the matrix language" (Haugen and Mithun 2003, 243), whose meanings are, or have been, intelligible to the general speech community (Loveday 1996; Irwin 2011), and which fulfill a limited set of lexical constraints compared to the full constraints on native and fully established Sino-Japanese loanwords (Itō and Mester 1999).

The incorporation of gairaigo into Japanese is realized by a number of processes: orthographical, phonological, morphological, semantic, and syntactic (Kay 1995; Daulton 1999; Daulton 2008; Horikawa 2012), with Honna (1995) identifying seven types of modification: semantic narrowing and shift, Japanese phrasings of English, tail abbreviation, acronyms, abbreviations of compounds, Japanese words combined with English loans, and word play (cited in Oshima 2002). Typically, assimilation orthographically (with the exception of initialisms) is achieved by transliteration into katakana (Japanese syllabic characters that function in a way similar to italics in English), and phonologically by the fragmenting of consonant clusters and syllabalization consistent with Japanese. Morphologically, loanwords of more than two syllables are often abbreviated (e.g. sūp $\bar{a}$ for supermarket) and compound nouns reduced to single items (e.g. pasokon for personal computer). Semantic change can vary from a slight change in nuance to a completely different meaning (e.g. baggen for a sale). Syntactic changes include the combining of a lexeme with suru, to do, to form a verb, as in the case of doraibu suru (to drive).

Studies show the "inexorable rise in the proportion of gairaigo vocabulary across most media since the first survey providing token data was carried out in 1906" (Irwin 2011, 20). Gairaigo used in the Asahi Shimbun newspaper, for example, increased fourfold from 1952 to over 10\% in 1997 (Oshima 2004). A corpus analysis of contemporary magazines by the National Institute for Japanese Language and Linguistics (NINJAL 2005) identified roughly 15,000 foreign loanwords in use. These made up a quarter of all types in the corpus, compared with roughly a third native Japanese, a third Sino-Japanese, and 6\% hybrids. More recently, Horikawa (2012) cites a 2010 katakana dictionary that includes over 48,000 loanwords. It has

Learner Corpus Research: LCR2013 Conference Proceedings 2015, BeLLS Vol. 6, BeLLS.uib.no 
been estimated that loanwords comprise between $5 \%$ and $10 \%$ of the Japanese lexicon (Stanlaw 2004; Daulton 2011), that 95\% function as nouns, and 85\% are of English origin (NINJAL 2005).

The extent of gairaigo usage in different written and spoken genres appears to vary considerably. Shibu and Sanada (1980) found gairaigo accounted for $10 \%$ of types and $3 \%$ of tokens in the speech of workers and college students. More recently, Itō (2003) found that $8 \%$ of types and $10 \%$ of tokens in Japanese pop lyrics were gairaigo. In contrast, much higher proportions of gairaigo were found in TV commercials by Takashi (1990) and in magazines by NINJAL (1994, 2005). In terms of subject areas, an NHK survey in 1995 (cited in Tomoda 2005) found that gairaigo were most frequently used in advertisements, politics and economics, entertainment and leisure, and sports.

In relation to English language acquisition, despite the distance between Japanese and English, English-based loanword cognates may give Japanese learners a 'head start' similar to that which speakers of European languages enjoy when learning other European languages (Odlin 1989). However, potential benefits of a large common lexicon must be tempered with the recognition that there are problems relating to partial semantic identity and difference in grammatical restrictions of the lexemes in question (Odlin 1989, 79). These considerations aside, it has been suggested that the considerable number of loanwords in the Japanese lexicon, especially those derived from English, provide a valuable resource for Japanese L2 learners of English (Brown and Williams 1985; Brown 1995; Kay 1995; Daulton 1999, 2007, 2008a, 2009, 2011). Numerous studies support this contention (Van Benthuysen 2004). Knowledge and awareness of gairaigo can facilitate lexical acquisition (Yoshida 1978), the comprehension of foreign lexis (Brown and Williams 1985; Kimura 1989), aural recognition and pronunciation (Hashimoto 1992), and the recognition and recall of vocabulary (Daulton 1998). Moreover, from a review of studies, Nation (2003) concludes that, in general, the conscious use of loanword cognate items can be an effective strategy for vocabulary expansion.

The use of gairaigo as a learning tool may, however, have potential disadvantages. Learners may not be aware of the language of origin and thus use an item inappropriately, Kay (1995) citing the example of the loanword arubaito used in English to refer to part-time work when, in fact, its origin is the German arbeit (work). The degree of phonological, semantic, and syntactic transformation that loanwords undergo in their integration into Japanese can have a negative effect on learners' ability to use spoken English (Olah 2007). Pronunciation is distorted (Yano 2001), and learners are largely unaware of the meaning of loanwords in their language of origin (Yamazaki 1997, 1998) and the semantic changes they have undergone (Tanaka and Tanaka 1995). As noted previously, the frequency of usage in different contexts can vary considerably, and high frequency of types does not necessarily correspond to high token counts. The NINJAL survey (2005) indicated that gairaigo comprised $25 \%$ of types but only $12 \%$ of tokens. Horikawa (2012), using a corpus of almost 19 million words, found only 338 types at a level of significance set at 30 or more per million. What these figures suggest is that specific borrowings and usage may be influenced by their functionality in Japanese and not necessarily correlate with patterns of employment in the original language, with consequent influences on learners' lexicons and word choices. Nouns are more likely than verbs to be crosslinguistically transferred (Marian and Kaushanskaya 2008), gairaigo adjectivals

Learner Corpus Research: LCR2013 Conference Proceedings 2015, BeLLS Vol. 6, BeLLS.uib.no 
are more likely to be used to modify gairaigo nouns (Stanlaw 1997; Bordilovskaya 2012), and distinctive (and potentially confusing) patterns of L1 usage emerge such as with the addition of the Japanese verb suru (to do) as in the case of katto-suru derived from to cut + suru (Mogi 2012).

Before the ensuing discussion on the role of loanwords in L2 production, clear distinctions must be made among the terms we employ. Gairaigo, as stated earlier, are loanwords, generally of English origin, used in Japanese. For example, sūpa is a gairaigo term indicating a supermarket or supermarkets. A loanword cognate refers to a loanword in Japanese which is a possible, or theoretical, source of lexical crosslinguistic transfer. For instance, sūp $\bar{a}$ may or may not expedite the acquisition of supermarket by Japanese L2 learners of English. A loanword cognate item, on the other hand, is an empirical term used to classify any word in English text (produced either by a NS or NNS) that has a corresponding loanword equivalent in Japanese. Supermarket is, thus, a loanword cognate item, with the corresponding loanword equivalent sūp $\bar{a}$ in Japanese. It must be emphasized that loanword cognate item is used to classify lexical items produced in text without attributing any intention or cognitive process on the part of the writer in the case of NNS writing, and for NS writing simply serves to determine expected frequencies of these lexical items. The distinction between loanword cognate and loanword cognate item is important as the authors are not addressing or making assumptions about the processes of crosslinguistic transfer, but are seeking to identify lexis in L2 production that may be derived from the L1 lexicon. Furthermore, while gairaigo is a point of reference, the analytical focus of this research is the measurable presence of loanword cognate items in text and the statistical relationship of such a presence to the lexicon of loanword cognates.

Daulton (2007, 2009, 2010) argues that the most frequent and well-established loanword cognate items are relatively stable across time and in usage, providing a valuable linguistic and cultural resource, and constituting "a useful built-in lexicon for Japanese learners of English" (2007, 15). English lexical items and their gairaigo equivalents provide interlingual cognate pairs - words which are similar in form if not entirely in meaning (Daulton 2008b). The orthographic transformation and rephonolization of gairaigo is compensated for by a "katakana filter", a psycholinguistic device that decodes such modifications and enables learners to identify and exploit cross-linguistic similarities (Daulton 2003, 2008b). In support, Brown (1995) found that L2 learners showed a preference for using loanwords in a cloze exercise, Daulton (1998) showed that learners could produce loanword cognate items more readily in response to prompts than L2 non-loanwords, and Uchida (2001) demonstrated that junior high school subjects were able to identify the L1-L2 correspondences for about half the unknown L2 words presented. That some learners are ambivalent about the resource gairaigo offers, Daulton (2011) attributes to inadequate information and the negative attitudes of some language instructors.

Daulton $(1999,2003,2007)$ further argues that the built-in gairaigo lexicon is not simply a resource but assists learners in identification and use of inflected forms and derivatives of specific loanword cognate items and actively encourages L2 learners to preferentially employ these items in their written output. Loanword cognates facilitate production, resulting in the relatively greater frequency of loanword cognate items in written texts - a phenomenon that Daulton (2007) terms "the borrowed word effect". In his 2007 study, prior to analyzing learners' writings,

$\overline{\text { Learner Corpus Research: LCR2013 Conference Proceedings 2015, BeLLS Vol. 6, BeLLS.uib.no }}$ 
an expectation of gairaigo usage was established by examining the number of correspondences between his database of commonly used gairaigo and high frequency words in the British National Corpus (as reported by Nation 2004). In the first 1000 most frequent words in the BNC list, 803 types were found to correspond to loanwords in Japanese, 548 families corresponded to loanwords, and 54.8\% of word families corresponded to loanwords. Calculations were made for the first 1000, second 1000, and third 1000 words, with an expected decline in the number of correspondences, but indicating that of the first 3000 words, 1808 words and 1356 families corresponded to loanwords. When analyzing the learners' texts, Daulton found a disproportionately higher frequency of loanword cognate items than would be expected from the number of loanwords corresponding to the BNC's most frequent 3000 words. This might be due to the comfort in using familiar and generalized vocabulary, lexis that Hasselgren (1994) terms "lexical teddy bears". Daulton's inference from the results is that, for Japanese L2 learners, gairaigo are the easiest to use, and that loanword cognates not only encourage overall production but also facilitate overall acquisition.

This review indicates that the integration of loanwords into Japanese is only accomplished by their significant modification, modification that some researchers (e.g. Otake 2008) have argued limit their usefulness in language acquisition and production. However, it is also noted that gairaigo is an important element in the lexicon of present-day Japanese, with a considerable number of loanword types utilized in fields as diverse as advertising, politics, economics, entertainment and leisure. Given their ubiquity, gairaigo may potentially have a valuable role in L2 acquisition. Daulton (e.g. 2007) consistently argues that gairaigo offer a means by which learners can access, acquire, and use loanword cognate items, the L2 words from which they are derived. A corpus analysis of frequencies of gairaigo usage in L2 written texts may indicate the veracity of Daulton's claims - and the importance of loanwords for Japanese learners of English. Based partially on Daulton's (2007) methodology, we further the investigation by using a slightly larger longitudinal learner corpus as well as a NS corpus to identify norms and answer the following research questions (NNS, or non-native speakers, indicating Japanese learners of English):

1. Does NNS writing show higher frequencies of loanword cognate item deployment than NS writing?

2. Given the claims that loanword cognates provide a valuable initial resource for NNS, does the frequency of loanword cognates items in learner writing decrease over time as writers' English vocabulary resources develop?

3. Given the variations in usage of gairaigo in different modes, fields and genres, do patterns of loanword cognate item deployment differ between narrative and argumentative genre writing within NNS writing and NS writing respectively?

4. Given the changes that loanwords undergo in their integration into Japanese and their employment within the language, does NNS writing exhibit patterns of loanword cognate item usage that deviate from NS writing?

Learner Corpus Research: LCR2013 Conference Proceedings 2015, BeLLS Vol. 6, BeLLS.uib.no 


\section{Data and Methodology}

\subsection{Corpus data collection}

In order to answer the research questions outlined, this research investigates the usage of loanword cognate items in a longitudinal learner corpus comprised of the English writing of 170 Japanese university student learners of English (NNS) and another corpus comprised of the writing of 29 native speakers (NS) of English (American university students aged 18-22 on short-term study abroad programs at Japanese Universities) in both narrative and argumentative genres. This provides two corpora for comparison: 1) The NS corpus comprised of two subcorpora (argumentative and narrative), and 2) the NNS corpus comprised of four subcorpora (argumentative and narrative writing at 2 time points).

The writing samples were obtained in strictly controlled conditions. Two writing prompts were presented to the writers, with one eliciting a narrative writing sample and the other an argumentative writing sample. For the Japanese learners, the prompts were presented in Japanese to avoid influence of lexical items within the prompts, and for the native speakers, in English as follows:

Prompt 1 Narrative: "Imagine two friends went shopping together last week. One friend returned home happy, the other friend returned home sad. Write a story about what happened. You have 20 minutes."

Prompt 2 Argumentative: "Studying English (a foreign language) abroad. Please write reasons for and against studying English (a foreign language) in another country. You have 20 minutes."

Writing was carried out with pen and paper. During the 40 minutes allowed for writing, speaking was not permitted, nor was the use of reference materials such as dictionaries. The same procedure was followed in the collection of samples at both points in time. For the Japanese learners, the writing samples were collected at two points in time, one year apart at the onset of their first and second year of English writing instruction in university. The handwritten samples were then digitally transcribed to text files, checked to be fair copies, and the files organized in a database in preparation for electronic text analysis. The researchers then proofread transcribed files and corrected spelling mistakes, where the attempted lexical item was obvious, in order to preserve and render identifiable (by wordlists) as many of the lexical items deployed by NNS as possible. The token counts for the resulting corpora are shown in Table 1.

Table 1. Token counts for NNS and NS corpora

\begin{tabular}{|c|c|c|}
\hline \multicolumn{3}{|c|}{ Narrative Writing (tokens) } \\
\hline NNS (Time 1) & NNS (Time 2) & NS \\
\hline 12,796 & 15,105 & 13,824 \\
\hline \multicolumn{3}{|c|}{ Argumentative Writing (tokens) } \\
\hline NNS (Time 1) & NNS (Time 2) & NS \\
\hline 13,570 & 16,230 & 13,143 \\
\hline
\end{tabular}

Learner Corpus Research: LCR2013 Conference Proceedings 2015, BeLLS Vol. 6, BeLLS.uib.no 


\subsection{Corpus preparation}

As the body of loanwords in Japanese has been shown to be primarily comprised of nouns, verbs, and adjectives (NINJAL 2005), and following Daulton's (2007) methodology, function words were removed leaving only content words for analysis. Table 2 shows the token counts for the corpora after function words and non-BNC words were removed.

Table 2. Token counts for NNS and NS corpora without function words

\begin{tabular}{llll}
\hline Narrative Writing (tokens) & & \\
\hline NNS (Time 1) & NNS (Time 2) & NS \\
\cline { 1 - 1 } Argumentative Writing (tokens) & 7,049 & 6,589 \\
\hline NNS (Time 1) & NNS (Time 2) & NS \\
\hline 6,793 & 8,274 & 6,749 \\
\hline
\end{tabular}

\subsection{Identification of loanword cognate items}

In order to determine which words could be treated as loanword cognate items, we adopt Daulton's approach of using the BNC 14,000 most frequent word family lists (Nation 2004) and modified versions of Daulton's (2007) subsets of these wordlists comprised only of corresponding loanwords. In total, two groups of four wordlists were created: (1) Three wordlists based on the BNC containing the first, second, and third most frequent word families wordlists respectively, and a fourth wordlist combining the 4,000-14,000 most frequent word families. (2) The corresponding loanword-only subsets of the four BNC lists described in (1) above. The raw frequencies of loanword cognate items and other words were calculated by submitting the individual subcorpora to vocabulary profile analysis using AntWord (Anthony 2013) and the previously described wordlists. This allowed calculation of ratios of loanword cognate items to non-loanword items in each of the subcorpora for comparison.

Comparison of the loanword cognate item and non-loanword item ratios between the subcorpora was carried out using the Log-likelihood G2 ratio statistic using a contingency table (cf. Rayson and Garside 2000) containing raw frequencies of loanword cognate items and non-loanword cognate items in two corpora or subcorpora (see Table 3), allowing determination of expected values and differences in deployment of loanword cognate items between: 1) NNS and NS argumentative / narrative writing, and 2) two time points of NNS writing in either genre. See also Table 5 for specific comparisons.

Table 3. Contingency table for calculation of log-likelihood

\begin{tabular}{|l|l|l|l|}
\hline Lexical items & Corpus 1 & Corpus 2 & Total \\
\hline Frequency of loanword cognate items & a & b & a+b \\
\hline Frequency of non-loanword cognate items & c-a & d-b & c + d-a-b \\
\hline Total & c & d & c + d \\
\hline
\end{tabular}

In addition, a keyword analysis of NNS writing was carried out using AntConc (Anthony 2013) and the NS corpus as reference corpora within the respective genres. This analysis reveals an unusually high frequency deployment of specific lexical

Learner Corpus Research: LCR2013 Conference Proceedings 2015, BeLLS Vol. 6, BeLLS.uib.no 
items and highlights those that may warrant closer examination in considering the nature of and implications of transfer from L1 to L2.

\section{Results}

3.1 Proportions of loanword cognate items

Each of the subcorpora was submitted to vocabulary profiling using the BNC 14,000 most frequent word family lists and corresponding subsets comprised of loanword cognates. Off-list items (i.e., proper nouns and words outside the BNC 14,000 most frequent word families) were excluded. Table 4 shows the raw frequencies of loanword cognate items and non-loanword items and normalized frequencies of loanword cognate items expressed as percentages.

Table 4. Frequencies and proportion of loanword cognate items across subcorpora

\begin{tabular}{|c|c|c|c|}
\hline Corpor & $\begin{array}{l}\text { Loanword cognate } \\
\text { items (tokens) }\end{array}$ & $\begin{array}{l}\text { Non-loanword BNC } \\
\text { items (tokens) }\end{array}$ & $\begin{array}{l}\text { Proportion loanword } \\
\text { cognate items }(\%)\end{array}$ \\
\hline NNS Nar. 1 & 2999 & 3019 & 50 \\
\hline NNS Nar. 2 & 3394 & 3655 & 48 \\
\hline NS Nar. & 2586 & 4003 & 39 \\
\hline NNS Arg. 1 & 3496 & 3297 & 51 \\
\hline NNS Arg. 2 & 4292 & 3982 & 52 \\
\hline NS Arg. & 2206 & 4273 & 34 \\
\hline
\end{tabular}

The ratio of loanword cognate items and non-loanword cognate $\mathrm{BNC}$ items were compared between the NNS corpora for both time points and NS corpora in each genre using the Log-likelihood G2 ratio (see Table 5 for results). The narrative writing of Japanese writers at both Time Point 1 (50\%) and Time Point 2 (48\%) exhibited significantly greater deployment of loanword cognate items than NS writing (39\%). Similarly, the argumentative writing of Japanese writers at both Time $1(51 \%)$ and Time $2(52 \%)$ exhibited significantly greater deployment of loanwords than NS writing (34\%). There appears to be a clear and persistent preference for loanwords cognate items among Japanese writers when compared with NSs.

Table 5. Results of log-likelihood G2 comparison of loanword cognate items between corpora

\begin{tabular}{|c|c|c|c|}
\hline Nature of comparison & $\begin{array}{l}\text { Corpora / Sub-corp } \\
(\% \text { Loanword Cog }\end{array}$ & $\begin{array}{l}\text { ra in Comparison } \\
\text { te Items) }\end{array}$ & Log-likelihood G2 \\
\hline \multirow{4}{*}{ NNS and NS } & NNS NAR 1 (50) & NS NAR (39) & $79.47 * * *$ \\
\hline & NNS NAR 2 (48) & NS NAR (39) & $61.79 * * *$ \\
\hline & NNS ARG 1 (51) & NS ARG (34) & $236.53 * * *$ \\
\hline & NNS ARG 2 (52) & NS ARG (34) & $268.43 * * *$ \\
\hline \multirow{2}{*}{ NNS Longitudinal } & NNS NAR 1 (50) & NNS NAR 2 (48) & 1.88 \\
\hline & NNS ARG 1 (51) & NNS ARG 2 (52) & 0.12 \\
\hline \multirow{3}{*}{$\begin{array}{l}\text { Comparison Between } \\
\text { Genres (NNS, NS) }\end{array}$} & NNS NAR 1 (50) & NNS ARG 1 (50) & 1.68 \\
\hline & NNS NAR 2 (48) & NNS ARG 2 (52) & $10.55 *$ \\
\hline & NS NAR (39) & NS ARG (34) & $24.11 * *$ \\
\hline
\end{tabular}

$*=\mathrm{p}<0.01 * *=\mathrm{p}<0.001 * * *=\mathrm{p}<0.0001$

Learner Corpus Research: LCR2013 Conference Proceedings 2015, BeLLS Vol. 6, BeLLS.uib.no 
Longitudinal comparison in both narrative and argumentative writing showed slight decrease and increase respectively over time; however, the difference was not significant. After a period of one year, the proportional deployment of loanword cognate items appears to have remained constant.

In the comparison between genres, NS writing showed significantly more loanword cognate items in narrative writing (39\%) compared with argumentative $(35 \%)$.

NNS writing showed no difference between narrative and argumentative writing at Time Point 1 (50\% and 51\% respectively) and a small significant difference Time Point 2 (48\% and 52\% respectively), but the direction of the difference was opposite to that observed in NS writing.

Overall, the findings confirm the intuitive expectation that NNSs would consistently deploy loanword cognate items more frequently than NSs. NS data shows that loanword cognate items may be more likely to appear in narrative texts, while NNS writing shows no differences in the deployment of loanword cognate items between the genres.

\subsection{Keywords in NNS writing}

In the list of keywords generated for the narrative NNS writing samples, of the 20 highest-ranked words (by Keyness calculated by log-likelihood ratio), 11 out of 20 at Time Point 1, and 10 out of 20 at Time Point 2 were loanword cognate items (see Table 6). In both cases, the three highest-ranked loanwords were buy, shopping and happy.

Table 6. Ranking of keywords by keyness in NNS narrative writing

\begin{tabular}{|c|c|c|c|c|c|c|}
\hline \multicolumn{4}{|c|}{ NNS Narrative Time Point 1} & \multicolumn{3}{|c|}{ NNS Narrative Time Point 2} \\
\hline Rank & Freq. & Keyness (LL) & Item & Freq. & Keyness (LL) & Item \\
\hline 1 & 186 & 205.201 & very & 304 & 232.205 & went \\
\hline 2 & 239 & 193.620 & went & 230 & 163.947 & buy (c) \\
\hline 3 & 201 & 159.659 & buy (c) & 163 & 150.860 & very \\
\hline 4 & 132 & 129.269 & bought & 231 & 126.405 & shopping (c) \\
\hline 5 & 200 & 121.246 & $\operatorname{shopping}(\mathbf{c})$ & 143 & 123.421 & bought \\
\hline 6 & 110 & 120.958 & happy (c) & 122 & 119.492 & happy (c) \\
\hline 7 & 83 & 98.861 & sad & 111 & 97.884 & shop (c) \\
\hline 8 & 87 & 86.161 & bag (c) & 90 & 95.277 & sad \\
\hline 9 & 71 & 77.491 & shoes (c) & 94 & 95.047 & shoes (c) \\
\hline 10 & 89 & 68.983 & girl (c) & 105 & 74.203 & girl (c) \\
\hline 11 & 68 & 58.476 & shop (c) & 81 & 67.067 & bag (c) \\
\hline 12 & 79 & 50.054 & want & 99 & 55.138 & clothes \\
\hline 13 & 66 & 47.505 & found & 77 & 50.295 & found \\
\hline 14 & 109 & 40.885 & wanted & 90 & 46.542 & last (c) \\
\hline 15 & 36 & 39.419 & ice (c) & 84 & 45.161 & want \\
\hline 16 & 27 & 39.341 & favorite & 34 & 36.729 & $\mathrm{~cd}$ \\
\hline 17 & 72 & 38.559 & last (c) & 34 & 36.729 & favorite \\
\hline 18 & 27 & 32.030 & cream $(c)$ & 43 & 34.603 & shirt (c) \\
\hline 19 & 64 & 30.663 & clothes & 79 & 34.598 & week \\
\hline 20 & 74 & 30.348 & home (c) & 86 & 32.068 & home (c) \\
\hline
\end{tabular}

Notes: items in bold followed by '(c)' indicate a loanword cognate item All Keywords in the table are significant $(\mathrm{p}<.0001)$

Learner Corpus Research: LCR2013 Conference Proceedings 2015, BeLLS Vol. 6, BeLLS.uib.no 
The selection of these items in particular is attributable to the prompt, which elicited writing in the thematic areas of shopping, travel, language and culture and will be discussed later. The deployment of loanword cognate items may also be explained by the preference for NNS writers to describe the shopping process as a central part of the story, whereas NS writing focused more on description and the thought processes of the protagonists of their narratives, where the associated lexis may not feature among loanword cognate items. The NS writing exhibited these specific loanword cognate items far less frequently.

The selection of lexical items by the NNSs favors loanword cognate items as well as other very high frequency (BNC) words. In order to determine the nature of the cross-linguistic transfer, the words were also analyzed in context (i.e., using concordance or n-grams) where grammatical and semantic usage can be clearly identified. Returning to the original text files of transcribed learner writing (to preserve the function words for analysis of grammaticality), examination of the loanword cognate item 'shopping' revealed the string 'go/went to shopping'. This ungrammatical insertion of the preposition 'to' may be traced back to the usage of shoppingu in Japanese. There were 60 and 70 instances of this string observed in NNS writing at Time Points 1 and 2 respectively. A Google search revealed 5.8 million hits for the construction shoppingu ni iku (lit. shopping to go) in Japanese.

$\begin{array}{lll}\text { ショッピング } & \text { に } & \text { 行く } \\ \text { shoppingu } & n i & i k u \\ \text { shopping } & \text { to-PURP } & \text { go } \\ \text { 'go shopping' } & & \end{array}$

The particle $n i$ in Japanese can be translated as to in English. It appears that this construction has been transferred from the Japanese usage to usage in English. A further example of loanword cognate item usage helps to illustrate another possible case of transfer from Japanese. The English lexical item 'sale' is widely used in Japanese as the gairaigo sēru, and in response to the narrative prompt, 20 instances of the word 'sale' were found in the NNS texts. Among these instances, 10 include the construction 'to be' + 'sale', For example: "This department is sale from today." or, "the bag was sale." The word 'sale' in both English and Japanese are semantically similar, however, syntactically the behavior is quite different. In English, the first construction would use the verb 'has' rather than 'be', that is "The department store has a sale from today." In the second instance, English usage conventions would call for the insertion of the preposition 'on' before sale, realized in the construction: 'The bag was on sale." In Japanese, these constructions are realized in ways that resemble those observed in the NNS English texts:

$\begin{array}{clllll}\text { (1) デパート } & \text { は } & \text { 今日 } & \text { から } & \text { セール } & \text { です } \\ \text { depato } & \text { wa } & \text { kyou } & \text { kara } & \text { sēru } & \text { desu } \\ \text { department } & \text { TOP } & \text { today } & \text { from } & \text { sale } & \text { is }\end{array}$

'The department store has a sale from today.'

The department was sale from today. (observed NNS construction)

Learner Corpus Research: LCR2013 Conference Proceedings 2015, BeLLS Vol. 6, BeLLS.uib.no 
(2)

$\begin{array}{llll}\text { バッグ } & \text { は } & \text { セール } & \text { だった } \\ \text { baggu } & w a & \text { sēru } & \text { datta } \\ \text { bag } & \text { TOP } & \text { sale } & \text { is-PAST }\end{array}$

'The bag was on sale.'

The bag was sale. (observed NNS construction)

Note that example (1) above shows that L1 usage may have transferred in the use of the verb 'be' instead of 'have', while in example (2), the verb 'be' is appropriate, but L1 usage conventions may have transferred resulting in the omission of the preposition 'on' before 'sale'.

Keyword analysis of NNS argumentative writing also revealed interesting usage patterns. Table 7 shows the 20 highest-ranked keywords in NNS argumentative writing at both time points by keyness, and again a high proportion of these are loanword cognate items $(\mathrm{T} 1=13 / 20 ; \mathrm{T} 2=14 / 20)$, even more so than was found in narrative writing (see Table 5). These results suggest overuse of the words listed, and in particular, those that may be categorized as loanword cognate items.

Examination of these items reveals that many are related to specific rhetorical functions in argumentative writing. The word think is perhaps overused to introduce the writers' opinion, and although it is not classified as a loanword cognate item, its usage may be a more general characteristic of learner writing (i.e., using a very limited set of basic constructions to realize rhetorical objectives).

Table 7. Ranking of keywords by keyness in NNS argumentative writing

\begin{tabular}{|c|c|c|c|c|c|c|}
\hline \multicolumn{4}{|c|}{ NNS Argumentative Time Point 1} & \multicolumn{3}{|c|}{ NNS Argumentative Time Point 2} \\
\hline Rank & Freq. & Keyness (LL) & Item & Freq. & Keyness (LL) & Item \\
\hline 1 & 447 & 500.739 & English (c) & 562 & 548.301 & English (c) \\
\hline 2 & 191 & 191.382 & $\operatorname{good}(\mathbf{c})$ & 276 & 249.508 & $\operatorname{good}(c)$ \\
\hline 3 & 159 & 156.281 & think & 167 & 137.235 & think \\
\hline 4 & 117 & 122.590 & bad (c) & 149 & 136.746 & bad (c) \\
\hline 5 & 153 & 110.247 & speak (c) & 147 & 129.557 & point (c) \\
\hline 6 & 154 & 105.723 & go (c) & 112 & 119.967 & points (c) \\
\hline 7 & 107 & 105.421 & point (c) & 186 & 117.097 & speak (c) \\
\hline 8 & 317 & 93.390 & abroad & 386 & 100.375 & abroad \\
\hline 9 & 233 & 76.952 & study (c) & 289 & 86.278 & study (c) \\
\hline 10 & 82 & 74.931 & want & 155 & 82.854 & go (c) \\
\hline 11 & 133 & 69.940 & very & 77 & 55.996 & want \\
\hline 12 & 52 & 61.365 & points (c) & 123 & 43.707 & very \\
\hline 13 & 143 & 50.979 & culture (c) & 124 & 42.746 & Japanese (c) \\
\hline 14 & 28 & 37.615 & demerit (c) & 33 & 38.236 & merit (c) \\
\hline 15 & 71 & 37.228 & Japan & 43 & 36.745 & skill (c) \\
\hline 16 & 27 & 36.272 & merit (c) & 77 & 32.043 & Japan \\
\hline 17 & 52 & 34.177 & food (c) & 74 & 31.630 & money (c) \\
\hline 18 & 24 & 32.242 & went & 25 & 28.967 & demerit (c) \\
\hline 19 & 92 & 31.797 & Japanese (c) & 24 & 27.808 & went \\
\hline 20 & 58 & 23.532 & know & 38 & 24.185 & speaker (c) \\
\hline
\end{tabular}

Notes: items in bold followed by '(c)' indicate a loanword cognate item All Keywords in the table are significant $(\mathrm{p}<.0001)$ 
On the other hand, there are a number of lexical items which are used to present the advantages and disadvantages of study abroad called for in the prompt. In the NNS writing, advantages and disadvantages are frequently expressed with the phrases "good point(s)" and "bad point(s)", and less frequent but high in keyness are the words merit and demerit. Note that the Japanese translation of the prompts used the loanwords meritto and demeritto, which may have influenced the selection of these lexical items.

NS writing in contrast did exhibit usage of words such as "advantage" and "disadvantage" to highlight the pros and cons of study abroad, but more often, other more sophisticated rhetorical devices were used for this purpose and in many cases do not include specific use of lexical items meaning 'advantage' or 'disadvantage'. The following are examples from the NS corpus which introduce advantages or disadvantages of study abroad:

(1) Unfortunately, there are also drawbacks to....

(2) Some reasons not to pursue this course of action are....

(3) On top of that, you get to...

(4) The reasons are obvious- ...

(5) Perhaps the most important consideration is whether...

Finally, the cause of the observed overuse of the string 'good/bad point' widely evident in NNS writing must be carefully considered to determine whether it is a feature specific to Japanese L2 English writing or common in English L2 writing by learners of various L1 backgrounds.

\section{Discussion}

As we have seen, gairaigo represent an integral element of the Japanese lexicon, fashioned over time to conform to the constraints of the language but often retaining sufficient similarities to their origins (cognation) for it to be argued that they provide an important resource for Japanese learners of English, expediting the acquisition and use of the L2 words from which they are derived. Daulton (2007) has demonstrated that this results in a relatively higher frequency usage of loanword cognate items in written texts or "borrowed word effect". The aim of this study was to extend the investigation by using a larger longitudinal learner corpus, an updated database of loanword cognates, as well as a NS corpus to identify norms. We sought to answer four research questions.

1. Does NNS writing show higher frequencies of loanword cognate item deployment than NS writing?

2. Given the claims that loanword cognates provide a valuable initial resource for NNS, does the frequency of loanword cognates items in learner writing decrease over time as writers' English vocabulary resources develop?

3. Given the variations in usage of gairaigo in different modes, fields and genres, do patterns of loanword cognate item deployment differ between narrative and argumentative genre writing within NNS writing and NS writing respectively?

4. Given the changes that loanwords undergo in their integration into Japanese and their employment within the language, does NNS writing exhibit patterns of loanword cognate item usage that deviate from NS writing?

$\overline{\text { Learner Corpus Research: LCR2013 Conference Proceedings 2015, BeLLS Vol. 6, BeLLS.uib.no }}$ 
Analysis of the corpus data reveals a marked and consistent pattern of overuse of loanword cognate items by Japanese learners of English in their English writing over time in comparison to their native speaker peers. This may be partially explained by the fact that it is L2 learner writing; it is to be expected that NNS writers deploy more high-frequency words (i.e. BNC first thousand most frequent word families), where a significant proportion are borrowed as loanwords. The keyword analysis does, however, show a very strong preference for particular loanword cognate items suggesting overreliance on these items by Japanese writers. Moreover, this trend does not appear to change over time suggesting that over the period of one year, these learners have continued to draw on a limited resource of lexical exponents and rhetorical strategies. The implication is that Japanese learners of English are using these loanword cognate items as lexical teddy bears (Hasselgren 1994) and this may operate simultaneously or overlap with a borrowed word effect.

The comparison of loanword cognate items in narrative and argumentative writing both within and between NS and NNS texts revealed a genre effect in NS writing. That is, loanword cognate items were more prevalent in NS narrative writing than in NS argumentative writing. This was not observed in NNS writing at Time Point 1, and a reverse tendency was observed at Time Point 2 (i.e. loanword cognate items were slightly more frequent in NNS argumentative writing at Time Point 2). One explanation may be that NNS writers are influenced more by their lexical resources than by the specific demands of different genres.

As to whether NNS usage of loanword cognate items deviates from NS usage, observations of the overuse of these items, and cases of ungrammaticality by NNSs, provide support for this proposition. The usage of merit and demerit is in no way erroneous, for example, but these are readily available and appropriate cognates for the expression of advantages and disadvantages. Similarly, usage of good point or bad point to discuss advantages and disadvantages is functional and appropriate to an extent. While writers are using these cognates as a resource, heavy reliance is evident and does not appear to diminish with time. It is also important to consider that word knowledge also entails understanding of the frequency and how it is used conventionally in a language (Jarvis and Pavlenko 2008). The overuse of certain loanword cognate items may indicate a lack of word knowledge in this sense. In addition, cases of ungrammaticality provide evidence for the aforementioned lack of word knowledge.

The present study provides support for Daulton's (2007) notion of a borrowed word effect. However, it does not appear as pronounced as in his findings due either to methodological differences or differences in the proficiency level and attitude toward English among the learners. His study of the effects of loanwords in production analyzes the writing of learners in an engineering program, in contrast to those in the present study, who are majoring in English-related studies. Differences between Daulton's and our study - proficiency level, educational context, exposure to English, and learner goals - might all impact on use of loanword cognate items. In the present study, the period of one year was not long enough for changes to be observed; however, it is possible that a decline would be seen after longer periods and at higher proficiency levels. In their review of landmark crosslinguistic influence research findings, Jarvis and Pavlenko (2008) note that as L2 proficiency increases, some transfer errors decline while others may emerge later, and it is therefore not a simple

Learner Corpus Research: LCR2013 Conference Proceedings 2015, BeLLS Vol. 6, BeLLS.uib.no 
linear process. It is not unlikely that as proficiency increases and more connections between gairaigo and English become salient, learners will deploy additional, perhaps lower frequency, loanword cognate items which may entail semantic or syntactic features in Japanese that influence usage in English adversely.

Caution must be exercised when making comparisons of learner English and native-speaker English. The more frequent use of certain lexical items by L2 learners may reflect not only linguistic proficiency and resources but also rhetorical choices related to culture or training. Indeed, Hinkel (2003), in her comparison of second language writers' texts, observed a very strong preference for the use of first person personal pronouns in the English texts of Japanese writers, which she attributes to L2 writing instruction aiming to develop fluency through personal narratives. She also found that Japanese writers' texts are characterized by a relatively high rate of use of logical/semantic conjunctions. While these features may be characterized as divergent from NS writing as overuse, it is important to consider that they may be stylistic or rhetorical choices that do not necessarily reflect proficiency.

As discussed earlier, whether these loanword cognates should be considered as a resource is an important issue. Daulton (2011), for example, is quite optimistic about loanwords and cites a number of studies, many focused on receptive language skills, which suggest loanword cognates facilitate recognition and recall of these words in English. Daulton suggests that "[i]t is likely that English loanwords in Japanese are promoting production itself, as having easily accessed vocabulary facilitates communication overall" $(2012,74)$, and although there is certainly an argument that cognates contribute to fluency, the issue of dependence and overreliance also suggests issues and challenges. The nature of the cognate and its usage in Japanese may result in L2 English usage which is ungrammatical or semantically inappropriate. This was observed in the NNS corpus as a widespread phenomenon in the string go to shopping, which as described earlier, may likely be attributed to the Japanese expression shoppingu ni iku grammatically realized with the insertion of the purposive particle $n i$ and translated in English as 'go shopping' or 'go to do shopping'. Although it does not interfere with the intelligibility, it is a clear example of the problem Odlin (1989) highlights in his discussion of cognates in language transfer noting that "[w]hile a pair of cognates may be semantically similar, there are often grammatical restrictions in one language, but not in another, and such restrictions can occasion difficulty" $(1989,79)$. The question of whether loanword cognates are in fact a resource depends on whether learners can surmount the inherent obstacles and deploy loanword cognate items at appropriate frequency in appropriate registers with recognition of and adherence to semantic conventions and grammatical restrictions in $\mathrm{L} 2$.

\subsection{Limitations of the study and future research}

This study was based on a relatively small learner corpus, which entails the associated problems with small corpus size. One important feature of this corpus, the fixed prompts for writing, allows for a specific comparison of lexical items brought to bear on the task, but also has a limiting and selective effect favoring lexis related to topical areas (i.e., shopping, leisure, and travel). The distribution of loanwords in Japanese may fall more in these areas, increasing the probability that loanwords are selected. Interrogation of more diverse Japanese learner corpora would shed light on the effect of prompt or topic area.

Learner Corpus Research: LCR2013 Conference Proceedings 2015, BeLLS Vol. 6, BeLLS.uib.no 
Further concerns are whether the frequencies of items identified as loanword cognates are the product of secondary education language texts used in Japan or a reflection of learner English in general. Japanese learner corpora must be compared with those of other L1 groups to distinguish the cognate items from learner language.

Since the time of this study, a follow-up study with a similar design has been carried out to compare frequency of loanword cognate items in English texts of writers from $16 \mathrm{~L} 1$ groups, including Japanese, using the ICLE corpus (Struc and Wood 2014). The findings show that in comparison with all other groups, respectively and as a whole, L1 Japanese writers deployed loanword cognate items at significantly higher frequency. This suggests that rather than simply being an artifact of learner language, overuse of loanword cognate items is a characteristic unique to L1 Japanese learners of English, at least among learners from the $16 \mathrm{~L} 1$ groups comprising the ICLE corpus.

Although Daulton's (2007) borrowed word effect result has been replicated to a degree, it is considerably less prominent than that observed in his study, which may be attributed to methodological differences or differences between the populations of writers contributing to the corpora in the respective investigations.

Finally, formulaic language research approaches offer opportunities to more clearly define the behavior of loanword cognate items in Japanese learner writing in English and highlight cases of semantic deviation and ungrammaticality associated with L1 usage. While concordances of NNS texts may direct researchers to repeated patterns of ungrammaticality, strings revealed through generating n-grams of various lengths could highlight the frequency of recurrent, or formulaic, patterns of language associated with loanword cognate items. Furthermore, interrogating relatively larger corpora is necessary to identify formulaic language in Japanese L2 English writing with greater confidence.

\section{References}

Anthony, L. 2012. AntConc (3.3.5m) [Computer Software]. Tokyo, Japan: Waseda University. http://www.antlab.sci.waseda.ac.jp/

Bordilovskaya, A. 2012. A study of loan color terms collocation in modern Japanese. Proceedings of the 34th Annual Meeting of the Cognitive Science Society, 13621367. (http://mindmodeling.org/cogsci2012/index.html)

Brown, J.B. 1995. Is Gairaigo English? The Internet TESL Journal 1 (2). http://iteslj.org/Articles/Brown-Gairaigo/

Brown, J. B. and C. J. Williams. 1985. Gairaigo: A latent English vocabulary base. Tohoku Gakuin University Review: Essays and Studies in Eibungaku , no. 76: 129-146.

Daulton, F.E. 1998. Japanese loanword cognates and the acquisition of English vocabulary. The Language Teacher 20 (1): 17-25.

Daulton, F. E. 1999. English loanwords in Japanese - The built-in lexicon. The Internet TESL Journal 5. http://iteslj.org/Articles/Daulton-Loanwords.html

Daulton, F.E. 2003. The effect of Japanese loanwords on written English production a pilot study. JALT Hokkaido Journal 7:3-12.

Learner Corpus Research: LCR2013 Conference Proceedings 2015, BeLLS Vol. 6, BeLLS.uib.no 
Daulton, F. E. 2007. Japanese learners' built-in lexicon of English and its effect on L2 production. The Language Teacher 31 (9): 15-18.

Daulton, F. E. 2008a. Japan's built-in lexicon of English-based loanwords. Clevedon: Multilingual Matters.

Daulton, F.E. 2008b. The 'katakana filter' and cognate recognition in EFL. The Ryukoku Journal of Humanities and Sciences 30 (1): 1-10.

Daulton, F.E. 2009. A defence of gairaigo. Ryukoku University International Center for Research Annual Report 18:41-45.

Daulton, F.E. 2010. Gairaigo stability. The Ryukoku Journal of Humanities and Sciences 31:55-62.

Daulton, F.E. 2012. On the origins of gairaigo bias: English learners' attitudes towards English-based loanwords in Japan. The Language Teacher 35 (6): 7-12.

Irwin, M. 2011. Loanwords in Japanese. Amsterdam: John Benjamins.

Hasselgren, A. 1994. Lexical teddy bears and advanced learners: A study into the ways Norwegian students cope with English vocabulary. International Journal of Applied Linguistics 4 (2): 237-260.

Hinkel, E. 2002. Second Language Writers' Text: Linguistic and Rhetorical Features. New Jersey: Lawrence Erlbaum Associates.

Honna, N. 1995. English in Japanese society: Language within language. Journal of Multilingual and Multicultural Development 16 (1-2): 45-62.

Horikawa, N. 2012. English loan words in Japanese: Exploring comprehension and register. Master's thesis. http://pdxscholar.library.pdx.edu/open_access_etds

Itō, J., and A. Mester. 1999. The phonological lexicon. In The Handbook of Japanese Linguistics, ed. N. Tsujimura, 62-100. Oxford: Blackwell.

Itō, M. 2003. Kayokyoku no naka no gairaigo gaikokugo (Loanwords and Foreign Words in Pop Songs). Nihongogaku 22 (7): 40-48.

Jarvis, S. and A. Pavlenko. 2008. Crosslinguistic Influence in Language and Cognition. New York: Routledge.

Kay, G. 1995. English loanwords in Japanese. World Englishes 14 (1): 66-76.

Kimura, M. 1989. The effect of Japanese loanwords on the acquisition of the correct range of meanings in English. Unpublished Master's thesis. Brigham Young University, Utah.

Loveday, L. 1996. Language contact in Japan: A socio-linguistic history. New York: Oxford University Press.

Loveday, L. 2008. Creating a mock-Western identity through English in Japanese ads: A study of Occidentalist invocations. Journal of Creative Communications 3 (2): 123-153.

Marian, V. and M. Kaushanskaya, M. 2008. Cross-linguistic transfer and borrowing in bilinguals. Applied Psycholinguistics 28: 369-390.

(DOI: 10.1017.S014271640707018X)

Mogi, T. 2012. Towards the lexicographic description of the grammatical behaviour of Japanese loanwords. Acta Linguistica Asiatica 2 (2): 21-34.

Nation, I. S. P. 2003. The role of the first language in foreign language learning. Asian-EFL Journal, 5. (http://www.victoria.ac.nz/lals/about/staff/publications/paul-nation/2003-Roleof-L1-Asian-EFL.pdf)

Nation, I. S. P. 2004. A study of the most frequent word families in the British National Corpus. In Vocabulary in a second language: Selection, acquisition

Learner Corpus Research: LCR2013 Conference Proceedings 2015, BeLLS Vol. 6, BeLLS.uib.no 
and testing, eds. P. Bogaards, and B. Laufer, 3-13. Amsterdam: John Benjamins.

NINJAL 2005. Linguistic survey of two million characters in contemporary magazines, 1994. http://www.ninjal.ac.jp/archives/goityosa/

Odlin, T. 1989. Language transfer. Cambridge: Cambridge University Press.

Olah, B. 2007. English loanwords in Japanese: Effects, attitudes and usage as a means of improving spoken English ability. Bunkyo Gakuin Daigaku Ningen Gakubu Kenkyū Kiyo 9 (1): 177-188.

Oshima, K. 2002. Semantic and structural shift patterns of gairaigo in Japan. Intercultural Communication Studies XI (4): 51-65.

Oshima, K. 2004. The movement of gairaigo usage: The case of the Asahi newspaper from 1952 to 1997. Bunkyo Gakuin Daigaku Gaikokugo Gakubu Bunkyo Gakuin Daigaku Tankidaigaku Kio 3:91-102.

Otake, M. P. 2008. Gairaigo - remodeling language to fit Japanese. Tokyo Seitoku University Faculty of Humanities Bulletin, no. 15:87-101.

Rayson, P. and R. Garside. 2000. Comparing corpora using frequency profiling. Proceedings of the workshop on Comparing Corpora, held in conjunction with the 38th annual meeting of the Association for Computational Linguistics (ACL 2000). 1-8 October 2000, Hong Kong, 1-6.

Shibu, S. and S. Sanada. 1980. Goi chosei to sono bunseki (A vocabulary survey and its analysis). In Nihonjin no chishiki kaiso ni okeru hanashikotoba no jitai (The State of Spoken Language Amongst Educated Japanese), Kokuritsu Kokugo Kenkyujo (National Institute for the Japanese Language), 63-82. Tokyo: Kokuritsu Kokugo Kenkyujo Nihongo Kyouiku Senta.

Stanlaw, J. 1997. Two observations on culture contact and the Japanese color nomenclature system. In Color categories in thought and language, eds. C.L. Hardin, and L. Maffi, 240-260. Cambridge: Cambridge University Press.

Stanlaw, J. 2004. Japanese English: Language and culture contact. Hong Kong: Hong Kong University Press.

Struc, N. and Wood, N. Loanwords and Learner Language in Learner Corpora. Paper presented at JALT 2014 International Conference on Language teaching and Learning, Tsukuba, Japan.

Takashi, K. 1990. A functional analysis of English borrowings in in Japanese advertising: linguistic and sociolinguistic perspectives. Doctoral dissertation, Georgetown University.

Tanaka, K., and S. Tanaka. 1995. A survey of Japanese sources on the use of English in Japan. World Englishes 14 (1): 117-135.

Tomoda, T. 2005. The loanword (gairaigo) influx into the Japanese language: Contemporary perceptions and responses. Unpublished doctoral dissertation, University of New South Wales.

Uchida, E. 2001. The use of cognate inferencing strategies by Japanese learners of English. Unpublished doctoral dissertation, University of Essex.

Van Benthuysen, R. V. 2004. Japanese EFL students' awareness of English loanword origins. Bunko Gakuin Daigaku Gaikokugo Gakubu Bunkyo Gakuin Tanki Daigaku Kio 4:169-74.

Yamazaki, T. 1997. Lack of awareness by Japanese university students of the inferences of Japanese English. Journal of the Faculty of Education, Shinshu University 90:41-50.

Learner Corpus Research: LCR2013 Conference Proceedings 2015, BeLLS Vol. 6, BeLLS.uib.no 
Struc and Wood

Yamazaki, T. 1998. Semantic recognition of loan words by Japanese university students. Journal of the Faculty of Education, Shinshu University 93:25-34.

Yano, Y. 2001. World Englishes in 2000 and beyond. World Englishes 20 (2): 119132.

Learner Corpus Research: LCR2013 Conference Proceedings 2015, BeLLS Vol. 6, BeLLS.uib.no 